\title{
Characterisation of Colloidal Particles in Seawater by Light Scattering
}

\section{Techniques}

Gireeshkumar Balakrishnan*, Fabienne Lagarde, Christophe Chassenieux, Taco Nicolai

IMMM UMR-CNRS6283, Le Mans Université, 72085 Le Mans Cedex 9, France.

*Corresponding author:

Dr. Gireeshkumar Balakrishnan

Postal address :IMMM UMR-CNRS6283, Le Mans Université, 72085 Le Mans Cedex 9, France.

Email address:Gireeshkumar.Balakrishnan_Nair@univ-lemans.fr

\section{ABSTRACT}

Static (SLS) and dynamic (DLS) light scattering techniques are assessed for their capacity to detect colloidal particles with diameters between $\mathrm{d}=0.1$ and $0.8 \mu \mathrm{m}$ at very low concentrations in seawater. The detection limit of the apparatus was determined using model monodisperse spherical polystyrene latex particles with diameters $0.2 \mu \mathrm{m}$ and $0.5 \mu \mathrm{m}$. It is shown that the concentration and size of colloids can be determined down to about $10^{-6} \mathrm{~g} / \mathrm{L}$. Seawater obtained from different locations in western Europe was characterized using light scattering. It was found that seawater filtered through $0.45 \mu \mathrm{m}$ pore size membrane filters was within the experimental error the same as that of ultrapure Milli-Q water containing the same amount of sea salt and no colloids could be detected with DLS. When the seawater was filtered through $0.8 \mu \mathrm{m}$ pore size filters, colloidal particles were detected. The measurements show that the concentration of colloids in the seawater samples is not higher than $10^{-6} \mathrm{~g} / \mathrm{L}$ and that they have an average diameter of about $0.6 \mu \mathrm{m}$. We stress that these particles are not necessarily nanoplastics. 
KEYWORDS. Nanoplastics, nanoparticles, seawater, colloids, static light scattering, dynamic light scattering

\section{INTRODUCTION}

The fate of plastics that are dumped in the sea is currently attracting much attention ${ }^{1}$. When discharged in the environment, plastics undergo mechanical (erosion, abrasion), chemical (photo-oxidation under UV radiation, hydrolysis) and biological (degradation by microorganisms) actions ${ }^{1-6}$, which leads to ageing and fragmentation of macroplastics into microplastics defined as plastic particles smaller than $5 \mathrm{~mm}^{7}$. Microplastics were found to be ubiquitous in the environment and in particular on the surface of the oceans. One important issue that has recently emerged is whether microplastics continue to fragment into colloidal particles with a diameter $\mathrm{d}<1 \mu \mathrm{m}$ that were called nanoplastics ${ }^{8,9}$ although in general particles are considered as nanoparticles only if they are smaller than $100 \mathrm{~nm}$ in at least one dimension.

Gigault et al. ${ }^{8}$ investigated the release of nanoplastics under UV light from weathered polyethylene and polypropylene fragments sampled from the environment. They observed that nanoplastics with a broad range of sizes were produced over a period of weeks. More recently, Ter Halle et al. ${ }^{10}$ investigated seawater collected near the surface of the North Atlantic subtropical gyre. The seawater was filtered through $1.2 \mu \mathrm{m}$ pore size filters, and the filtrate was inspected for the presence of nanoplastics with dynamic light scattering. Particles with diameters between $1 \mathrm{~nm}$ and $1 \mu \mathrm{m}$ were detected in seawater that was concentrated by a factor 200 . It was 
suggested that these particles were mostly nanoplastics formed by degradation of microplastic, but the authors did not provide an estimate of the concentration of nanoplastics in the seawater.

The presence of such small particles raises questions about their environmental concentration and their potential accumulation in the trophic chain. Indeed, due to their small size and specific properties, nanoplastics can be ingested by a very large range of aquatic organisms and can interact with membranes and cells ${ }^{4}$. Nanoplastics dispersed in the seawater could be part of the 'lost plastic' that has been dumped in the sea, but is no longer observed at the surface 5,11 . Detection and quantification of nanoplastics in all aquatic compartments are, therefore, an urgent need. A major difficulty is that even though the total amount of plastic in the sea is huge, the concentration of nanoplastics in seawater is still expected to be very low.

It is possible to characterize the size and shape of individual nanoplastics using microscopy ${ }^{12}$, but it is difficult to quantify their concentration and average size distribution. Static and dynamic light scattering techniques have the potential to yield both the average size and the concentration of colloidal particles even if they are present in very low concentrations. The aim of the investigation reported here was twofold. First, we critically assess the potential of these light scattering techniques to quantify the concentration and size distribution of model nanoplastics in the form of polystyrene latex particles with $\mathrm{d}<0.8 \mu \mathrm{m}$ dispersed in seawater. After a brief review of the relevant light scattering theory aimed for researchers that are not very familiar with the technique, we will compare theoretical with experimental results on these model nanoplastics in order to demonstrate the limits of the technique for current state of art light scattering equipment. Then we will discuss light scattering measurements on seawater sampled at different places near the coast of Western Europe. We show that the concentration of colloids with $\mathrm{d}<0.45 \mu \mathrm{m}$ is less than $10^{-6} \mathrm{~g} / \mathrm{L}$ and cannot be characterized by light scattering. The 
concentration of colloids with $0.45<\mathrm{d}<0.8 \mu \mathrm{m}$ is approximately $10^{-6} \mathrm{~g} / \mathrm{L}$ and can be characterized if care is taken. Of course, colloids that are detected in seawater do not necessarily consist of plastic as mineral colloids are expected to be present. We will mention in the Discussion section how the light scattering results depend on the type of material.

\section{THEORY}

Here we briefly resume the theory of static and dynamic light scattering techniques as they are applied for the characterization of dilute colloidal particle suspensions. For more detailed information about the techniques see refs ${ }^{13-18}$

\section{Static light scattering}

Light scattering results are often expressed in terms of the Rayleigh ratio $\left(\mathrm{R}_{\theta}\right)$, which is related to the scattered light intensity (I) in dilute solutions as follows:

$\mathrm{R}_{\theta}=\frac{\mathrm{I}-\mathrm{I}_{\mathrm{sol}}}{\mathrm{I}_{\mathrm{i}}} \frac{\mathrm{R}^{2}}{\mathrm{~V}}$

where $I_{i}$ and $I_{s o l}$ are intensities of the incident light and the light scattered by the solvent, respectively, $\mathrm{R}$ is the distance between the scattering volume and the detector and $\mathrm{V}$ is the scattering volume. We are considering here that the incident light is vertically polarized, which is the case for most modern light scattering equipment. As it is often difficult to determine with precision $\mathrm{R}$ and $\mathrm{V}$, one measures the intensity relative to a standard with known $\mathrm{R}_{\theta}$ taking into consideration that V depends on the refractive index (n) of the medium.

$\mathrm{R}_{\theta}=\frac{\mathrm{I}-\mathrm{I}_{\text {sol }}}{\mathrm{I}_{\mathrm{st}}}\left(\mathrm{n} / \mathrm{n}_{\mathrm{st}}\right)^{2} \mathrm{R}_{\mathrm{st}}$ 
where $I_{s t}, R_{s t}$ and $n_{s t}$ are the scattering intensity, the Rayleigh ratio and the refractive index of the standard. For simplicity, we will assume here the Rayleigh-Gans approximation, which is valid for dispersed particles smaller than the wavelength of the incident light $(\lambda)$ or with a refractive index very close to that of the solvent. In this case, $\mathrm{R}_{\theta}$ is related as follows to the molar mass (M) and weight concentration $(\mathrm{C})$ of the dispersed particles:

$\mathrm{R}_{\theta}=$ K. C.M.S(q)

where $\mathrm{K}$ is an optical constant that depends on the refractive index increment $(\delta \mathrm{n} / \delta \mathrm{c})$ and $\lambda$ :

$\mathrm{K}=4 \pi^{2} \mathrm{n}^{2}\left(\frac{\delta \mathrm{n}}{\delta \mathrm{c}}\right)^{2} / \lambda^{4} \mathrm{~N}_{\mathrm{a}}$

with $\mathrm{N}_{\mathrm{a}}$ Avogadro's number. $\mathrm{S}(\mathrm{q})$ is the structure factor and describes the dependence of the scattering intensity on the scattering wave vector (q). The latter depends on the angle of observation $(\theta)$ at which the experiment is done:

$\mathrm{q}=\frac{4 \pi \mathrm{n}}{\lambda} \sin \left(\frac{\theta}{2}\right)$

For very dilute solutions that we are considering here, $S(q)$ depends only on the shape of the particles, e.g. for homogeneous spheres of diameter $\mathrm{d}$ :

$\mathrm{S}(\mathrm{q})=\left[3\left(\sin \left(\frac{\mathrm{qd}}{2}\right)-\frac{\mathrm{qd}}{2} \cos \left(\frac{\mathrm{qd}}{2}\right)\right) /\left(\frac{\mathrm{qd}}{2}\right)^{3}\right]^{2}$

For particles of any shape the initial q-dependence of $S(q)$ can be expressed as a series expansion in terms of the radius of gyration $\left(\mathrm{R}_{\mathrm{g}}\right)$ :

$S(q)=\left[1+\frac{q^{2} R_{g}^{2}}{3}+. .\right]^{-1} \quad$ q. $R_{g}<1$ 
Notice that $\mathrm{S}(\mathrm{q})=1$ for $\mathrm{qR}_{\mathrm{g}}<<1$ so that one can determine $\mathrm{M}$ by extrapolation to $\mathrm{q}=0$ for any particle.

So far we considered only monodisperse spherical particles. If the suspension contains particles with a range of sizes, the total scattering intensity is simply the integral of the contribution by particles of each size:

$\mathrm{R}_{\theta}=\mathrm{K} \int \mathrm{C}(\mathrm{d}) \mathrm{M}(\mathrm{d}) \mathrm{S}(\mathrm{q}, \mathrm{d}) \delta \mathrm{d}$

In this case, one obtains the weight average molar mass $\left.\mathrm{M}_{\mathrm{w}}=\int \mathrm{C}(\mathrm{d}) \mathrm{M}(\mathrm{d}) \delta \mathrm{d} / \mathrm{C}\right)$ at $\mathrm{q} \rightarrow 0$

independent of the shape of the particles.

As was mentioned above, the Rayleigh-Gans approximation is valid only for particles much smaller than $\lambda$ or with a refractive index close to that of the solvent. If this is not the case, the Mie theory needs to be used. Routines that calculate the q-dependent scattering intensity for spherical particles using the Mie theory are freely available on the internet, e.g. http://www.philiplaven.com/mieplot.htm.

\section{Dynamic light scattering}

With DLS one determines the correlation between the intensity at a given time with that at a delay time (t) later. The average over many starting times yields the normalized autocorrelation function of the scattered light intensity:

$g_{2}(t)=\frac{\langle I(0) I(t)\rangle}{\langle I\rangle^{2}}$ 
$\mathrm{g}_{2}(\mathrm{t})$ is related to the normalized electric field autocorrelation function $\left(\mathrm{g}_{1}(\mathrm{t})\right)$ through the socalled Siegert relation:

$g_{2}(t)-1=\beta\left[g_{1}(t)^{2}+\frac{\langle\delta N(0) \delta N(t)\rangle}{\langle N\rangle^{2}}\right]$

The prefactor $\beta$ is smaller than unity and depends on the optical set-up. The second term in Eq.10 reflects the fluctuation in the number of particles $(\mathrm{N})$ that are present in the scattering volume. For a dilute suspension of monodisperse particle with $\mathrm{q} . \mathrm{d}<1, \mathrm{~g}_{1}(\mathrm{t})$ decreases exponentially:

$g_{1}(t)=\exp \left(\frac{-t}{\tau}\right)$

with a relaxation time $\tau$ that is related to the diffusion coefficient of the particles (D):

$\tau=\left(\mathrm{Dq}^{2}\right)^{-1}$

The diffusion coefficient of spherical particles is related to their diameter and the solvent $\operatorname{viscosity~}(\eta)$ :

$\mathrm{D}=\frac{\mathrm{kT}}{3 \pi \eta \mathrm{d}}$

where $\mathrm{k}$ is the Boltzman constant and $\mathrm{T}$ is the absolute temperature. The same relationship can be used to calculate a hydrodynamic diameter $\left(d_{h}\right)$ of particles of any shape. If $q \cdot d_{h}>1$ one needs to consider rotational motion and internal dynamics unless the particles are spherical, rigid and homogeneous.

If the suspension contains particles with different size, the autocorrelation function determined by DLS is the integral of exponential decays corresponding to each size with amplitudes $\left(A\left(d_{h}\right)\right)$ proportional to their scattering intensity: 
$g_{1}(t)=\int A(\tau) \exp \left(\frac{-t}{\tau}\right) \delta \tau$

By fitting $g_{1}(t)$ to Eq.14, it is possible to determine the relaxation time distribution and the corresponding size distribution of the particles in the suspension. It is important to realize though that for a given mass concentration and if q.d $<1$, larger particles carry a stronger weight in the average, because they scatter more light. If $\mathrm{q} . \mathrm{d}<1$ for all particles the average relaxation time corresponds to the $\mathrm{z}$-average hydrodynamic diameter. In practice, most often the average of the relaxation rate $\left(\tau^{-1}\right)$ is used to calculate the $\mathrm{z}$-average hydrodynamic diameter $\mathrm{d}_{\mathrm{hz}}$ :

$\mathrm{d}_{\mathrm{hz}}=\left[\int \mathrm{C}\left(\mathrm{d}_{\mathrm{h}}\right) \mathrm{M}\left(\mathrm{d}_{\mathrm{h}}\right) \mathrm{d}_{\mathrm{h}}{ }^{-1} \delta \mathrm{d}_{\mathrm{h}} /\left(\mathrm{CM}_{\mathrm{w}}\right)\right]^{-1}$

The current state of the art DLS equipment allows one to determine autocorrelation functions over a very broad range of delay times. Therefore it should be straightforward to determine the size of nanoplastics with DLS as long as the particle concentration is sufficiently high so that the intensity scattered by the particles is in excess of that of water. However, when the concentration is very low one needs to consider the fluctuation in the number of particles that are present in the scattering volume, see Eq. 10. The number of particles in $\mathrm{V}$ is $\mathrm{N}=\mathrm{C} \cdot \mathrm{V} \cdot \mathrm{N}_{\mathrm{a}} / \mathrm{M}$ with $V \approx 0.3 \mathrm{~mm}^{3}$ for the apparatus used in experiments described below. We may consider that the effect is negligible if $\mathrm{N}>30$, which is the case if $\mathrm{C}>5 \times 10^{-7} \mathrm{~g} / \mathrm{L}$ for $\mathrm{d}=0.2 \mu \mathrm{m}$ and $\mathrm{C} \geq 10^{-5}$ $\mathrm{g} / \mathrm{L}$ for $\mathrm{d}=0.5 \mu \mathrm{m}$, assuming spherical particles with density $\rho=1 \mathrm{~g} / \mathrm{cm}^{3}$.

For monodisperse, rigid, homogeneous, spherical particles the relaxation time does not depend on q. However, this is not true for polydisperse samples, because the relative intensity scattered by particles with different sizes depends on q if q.d $>1$. In general, for polydisperse 
particles, the measured value of $d_{h}$ increases with decreasing $q$ until $q$ is smaller than the inverse of the true z-average hydrodynamic diameter. 


\section{MATERIALS AND METHODS}

\section{Materials}

Model polystyrene latex particles with diameter $\mathrm{d}=0.2 \mu \mathrm{m}$ (Thermofisher, catalog number: 5020A) and $\mathrm{d}=0.5 \mu \mathrm{m}$ (Polysciences, catalog number: 15700) were used as received. According to the provider, the 0.5 -micron particles are negatively charged due to the presence of carboxylate groups on the particle surface, whereas the 0.2-micron particles contain a trace amount of surfactant to inhibit aggregation. The density of the polystyrene particles was given by the provider as $1.05 \mathrm{~g} / \mathrm{ml}$. The solid content of the latex suspensions was $10 \mathrm{wt} \%$ and $2.5 \mathrm{wt} \%$ for $d=0.2 \mu \mathrm{m}$ and $d=0.5 \mu \mathrm{m}$, respectively. Particle suspensions were prepared by dilution with salt-free Milli-Q water at different concentrations: $\mathrm{C}=10^{-3}, 10^{-4}, 10^{-5}$ and $10^{-6} \mathrm{~g} / \mathrm{L}$.

Samples of seawater (about $2 \mathrm{~L}$ ) were taken by hand near the surface at different locations near the coast of France, Spain, and the Netherlands; Roscoff $\left(48^{\circ} 43^{\prime} 35.9^{\prime \prime} \mathrm{N}\right.$ $\left.3^{\circ} 58^{\prime} 57.0^{\prime \prime} \mathrm{W}\right)$, Challans $\left(47^{\circ} 03^{\prime} 49.4^{\prime \prime} \mathrm{N} \quad 2^{\circ} 00^{\prime} 41.2^{\prime \prime} \mathrm{W}\right)$, Toulon $\left.43^{\circ} 07^{\prime} 15.8^{\prime \prime} \mathrm{N} \quad 5^{\circ} 55^{\prime} 28.1^{\prime \prime} \mathrm{E}\right)$, (Lanzarote $\left(28^{\circ} 57^{\prime} 23.8^{\prime \prime} \mathrm{N} 13^{\circ} 33^{\prime} 16.6^{\prime \prime} \mathrm{W}\right)$ and Wassenaar $\left(52^{\circ} 08^{\prime} 55.5^{\prime \prime} \mathrm{N} 4^{\circ} 19^{\prime} 46.6^{\prime \prime} \mathrm{E}\right)$ in plastic or glass bottles that had been extensively rinsed with the same seawater. At one of these locations (Toulon), seawater was taken both near the surface and, by divers, at a depth of $10 \mathrm{~m}$. The samples were filtered through Acrodisc nylon membrane filters with pore sizes of $0.45 \mu \mathrm{m}$ or MF-Millipore cellulose ester membrane filters with pore sizes of $0.8 \mu \mathrm{m}$. No colloidal particles could be detected with DLS in Milli-Q water filtered through $0.45 \mu \mathrm{m}$ pore size filters. When colloid free Milli-Q water was filtered through the $0.8 \mu \mathrm{m}$ filters colloidal particles were detected with DLS showing that these filters released particles. Therefore, it was necessary to wash the filters by filtering about $50 \mathrm{ml}$ of Milli-Q water until release of particles was no longer 
detected by static and dynamic light scattering. A number of other commercial filters were tested (Acrodisc glass membrane filters $(1 \mu \mathrm{m})$, Whatman poly (ether sulphone) membrane filters $(0.8$ $\mu \mathrm{m})$, Whatman glass fiber filter $(1.5 \mu \mathrm{m}))$, but they released more particles and were therefore discarded. We have tested the retention of the particles smaller than the pore size by comparing the scattering intensity of latex particles before and after filtration and found it to be negligible. In addition, we did not find that the scattering intensity decreased further if filtered solutions were filtered a second time.

\section{Methods}

Dynamic and static light scattering measurements were done using a commercial apparatus ALV/CGS3 (ALV-Langen, Germany). The light source was a He-Ne laser with wavelength $\lambda=632 \mathrm{~nm}$. The temperature was controlled by a thermostat bath to $20 \pm 0.2^{\circ} \mathrm{C}$. Measurements were made at angles of observation $(\theta)$ between 13 and 150 degrees. Intensity autocorrelation functions were obtained using a digital multi-tau correlator. We have used toluene as the standard for which $\mathrm{R}_{\theta}=1.35 \times 10^{-5} \mathrm{~cm}^{-1}$ at $\lambda=632 \mathrm{~nm}$.

\section{Results}

\section{Model particles}

We tested the limitations for static and dynamic light scattering measurements for our equipment with monodisperse polystyrene latex particles with $d=0.2 \mu \mathrm{m}$ and $\mathrm{d}=0.5 \mu \mathrm{m}$. Figure 1 shows $R_{\theta}$ as a function of $q$ for the aqueous latex suspensions at $C=10^{-3}, 10^{-4}, 10^{-5}$ and $10^{-6}$ g/L. For comparison we also show the results for pure Milli-Q water. From the density and the size of the particles it is straightforward to calculate the corresponding number concentrations: 
$2.3 \times 10^{11}, 2.3 \times 10^{10}, 2.3 \times 10^{9}$ and $2.4 \times 10^{8}$ particles per liter for $\mathrm{d}=0.2 \mu \mathrm{m}$ and $1.5 \times 10^{10}, 1.5 \times 10^{9}$, $1.5 \times 10^{8}, 1.5 \times 10^{7} \mathrm{p} / \mathrm{L}$ for $\mathrm{d}=0.5 \mu \mathrm{m}$. The dashed lines in Figure 1 represent fits to Eq. 3 and Eq. 6 with $\mathrm{d}=0.2 \mu \mathrm{m}$ and $\mathrm{d}=0.50 \mu \mathrm{m}$, whereas the solid lines represent fits to the Mie theory. The Rayleigh-Gans approximation (Eq. 3) gave similar results for the smaller particles, but the Mie theory described the experimental results better for the larger particles at higher q-values. The experimental values of $R_{\theta}$ for pure water found in this investigation are in good agreement with the value reported in the literature ${ }^{19}$ and is shown for comparison in Figure 1a.

It is important to realize that as a consequence of the steep decrease of $R_{\theta}$ with increasing $q$ for $\mathrm{q}>\mathrm{d}^{-1}$ suspensions of the smaller particles actually scattered more light for $\mathrm{q}>2 \times 10^{7} \mathrm{~m}^{-1}$ than those of the larger particles at the same concentration. The scattering intensity of the smaller latex suspension was much larger than that of water down to $\mathrm{C}=10^{-5} \mathrm{~g} / \mathrm{L}$ over the whole accessible q-range. However, $\mathrm{R}_{\theta}$ of the larger latex suspension at $\mathrm{C}=10^{-5} \mathrm{~g} / \mathrm{L}$ approached that of water at the highest q-values. As a general feature, the scattering intensity by suspensions of homogeneous spherical particles at a fixed mass concentration increases with increasing size for q.d $<<1$, but decreases for q.d $>1$ as can be clearly seen from Figure 1. At a given value of $q$ and $\mathrm{C}, \mathrm{R}_{\theta}$ is largest for particles with $\mathrm{d} \approx 2 \pi / \mathrm{q}$. It is, therefore, necessary to do light scattering measurements at small q-values if very low concentrations of large particles are investigated. This is illustrated here for particles with $\mathrm{d}=0.5 \mu \mathrm{m}$ for which the scattering intensity is close to that of water at $\mathrm{C} \leq 10^{-5} \mathrm{~g} / \mathrm{L}$ if $\mathrm{q}>2 \times 10^{7} \mathrm{~m}^{-1}$, i.e. if $\theta>70^{\circ}$, but at smaller angles they still scatter orders of magnitude more light than water even at $\mathrm{C}=10^{-6} \mathrm{~g} / \mathrm{L}$, see fig. $1 \mathrm{~b}$. 

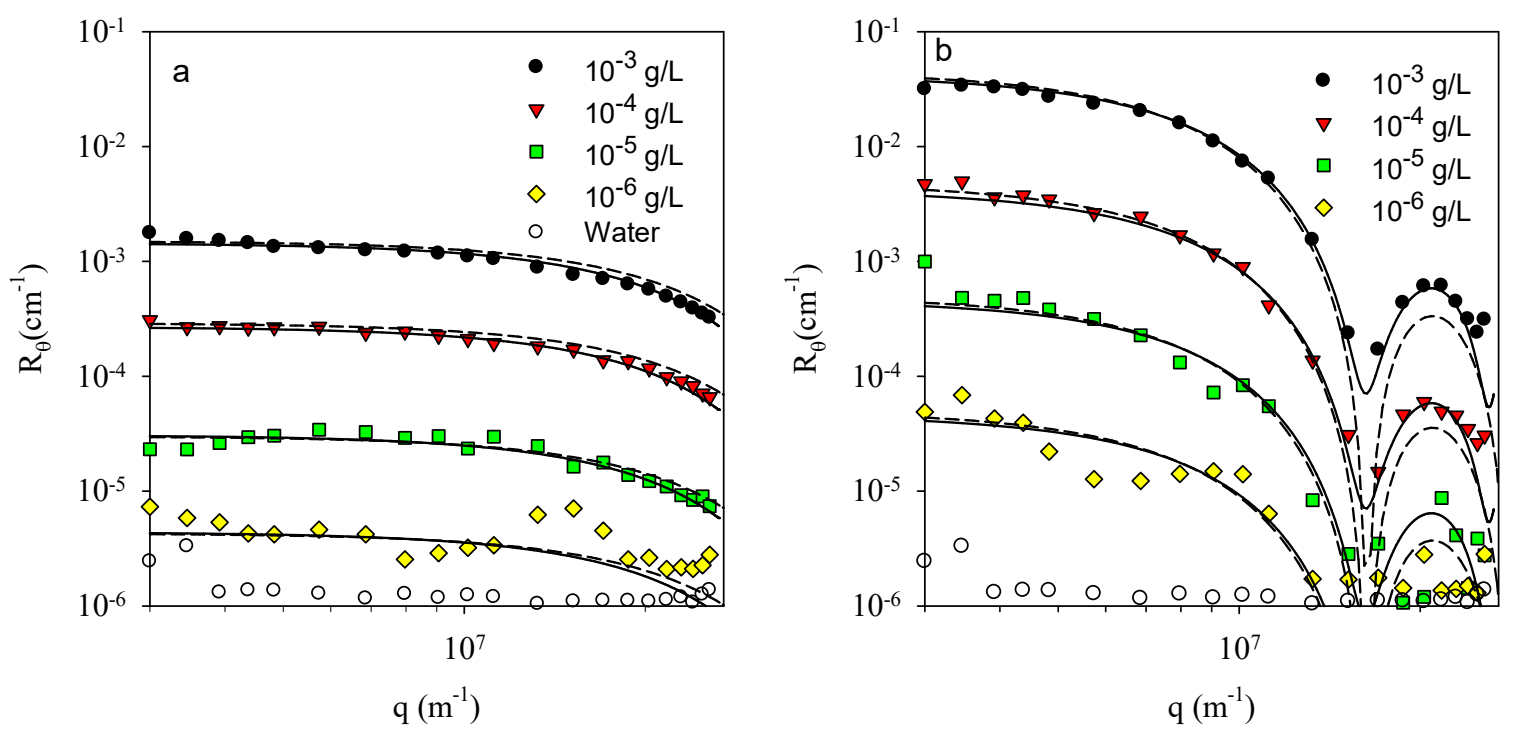

Figure 1. Dependence of the Rayleigh ratio on the scattering wave vector for suspensions of latex particles with $\mathrm{d}=0.2 \mu \mathrm{m}$ (a) or $\mathrm{d}=0.5 \mu \mathrm{m}$ (b) at different concentrations. The dashed and solid lines represent fits to Eq. 3 and Eq. 6 and the Mie theory, respectively.

As was mentioned above, if the number of particles in the scattering volume $(\mathrm{N})$ is not large one needs to consider the fluctuation of $\mathrm{N}$ in time due to diffusion of particles in and out of the scattering volume, see eq.10. This effect can be clearly seen from the time dependence of the intensity at different concentrations. Figure 2 shows examples of $\mathrm{R}_{\theta}$ as a function of time for the larger latex particles at $\mathrm{C}=10^{-4}, 10^{-5}$ and $10^{-6} \mathrm{~g} / \mathrm{L}$ at $\mathrm{q}=3.9 \times 10^{6} \mathrm{~m}^{-1}\left(\theta=17^{\circ}\right)$. For each solution, three measurements were done for a duration of $15 \mathrm{~min}$. The average value of $\mathrm{R}_{\theta}$ decreases in proportion to the concentration, but slow fluctuations became significant for $\mathrm{C}=10^{-5} \mathrm{~g} / \mathrm{L}$ and were more important for $\mathrm{C}=10^{-6} \mathrm{~g} / \mathrm{L}$. The scattering volume of the apparatus used here was approximately $0.3 \mathrm{~mm}^{3}$. The average number of particles in this volume was 45 at $\mathrm{C}=10^{-5} \mathrm{~g} / \mathrm{L}$ and less than 5 at $\mathrm{C}=10^{-6} \mathrm{~g} / \mathrm{L}$. It takes the latex particles about $10^{3} \mathrm{~s}$ to diffuse $0.1 \mathrm{~mm}$, which 
explains why the fluctuations in $\mathrm{R}_{\theta}$ are very slow. As a consequence, one needs to average over very long time periods to obtained accurate averages.
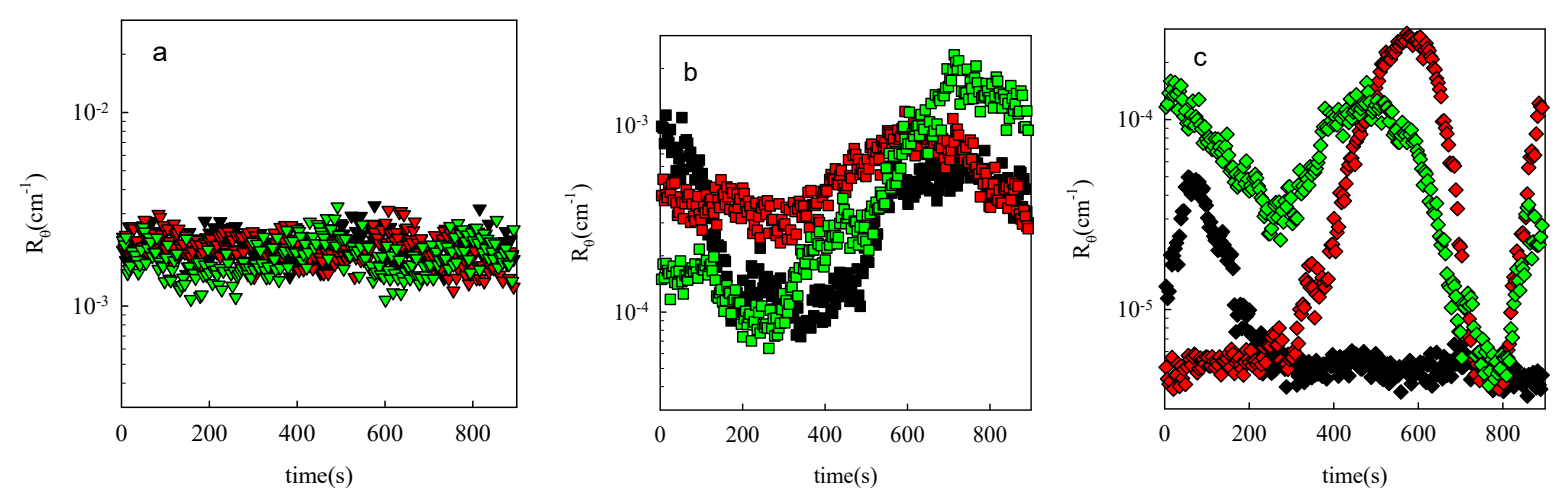

Figure 2. Time dependence of $R_{\theta}$ for suspensions of latex particles $(d=0.5 \mu \mathrm{m})$ at $C=10^{-4}$ (a), $10^{-5}(\mathrm{~b})$ and $10^{-6}(\mathrm{c}) \mathrm{g} / \mathrm{L}$ at $\mathrm{q}=3.9 \times 10^{6} \mathrm{~m}^{-1}\left(\theta=17^{\circ}\right)$. Three measurements are shown for each concentration.

Dynamic light scattering measurements could not be done reliably for suspensions of the larger latex particles at $\mathrm{C}=10^{-6} \mathrm{~g} / \mathrm{L}$, because the average number of particles in the scattering volume was too low to obtain reliable results. Figure 3 a shows intensity autocorrelation functions obtained at different scattering vectors for latex particles with $\mathrm{d}=0.5 \mu \mathrm{m}$ at $\mathrm{C}=10^{-5} \mathrm{~g} / \mathrm{L}$. The correlation functions were analyzed using Eq. 14 assuming a log-normal size distribution. The solid lines in Figure 3a represent the fit results, and the corresponding size distributions are shown in Figure 3b. The q-dependence of the z-average hydrodynamic diameter is shown as an inset of Figure 3b. Even at this low concentration, the $d_{h z}$ values found with DLS were within $20 \%$ of the nominal value at low q-values and within $40 \%$ at high q-values. The lower precision at higher q-values was caused by the low scattering intensity, see fig. 1 . Notice that the correlation functions shown in fig. 3a did not all reach zero, which was due to the slow 
fluctuation of the number of particles in the scattering volume discussed above that causes an additional slow relaxation time at very low particle concentrations. This problem was much exacerbated at $\mathrm{C}=10^{-6} \mathrm{~g} / \mathrm{L}$ and is the reason why no reliable DLS results could be obtained for that system. 

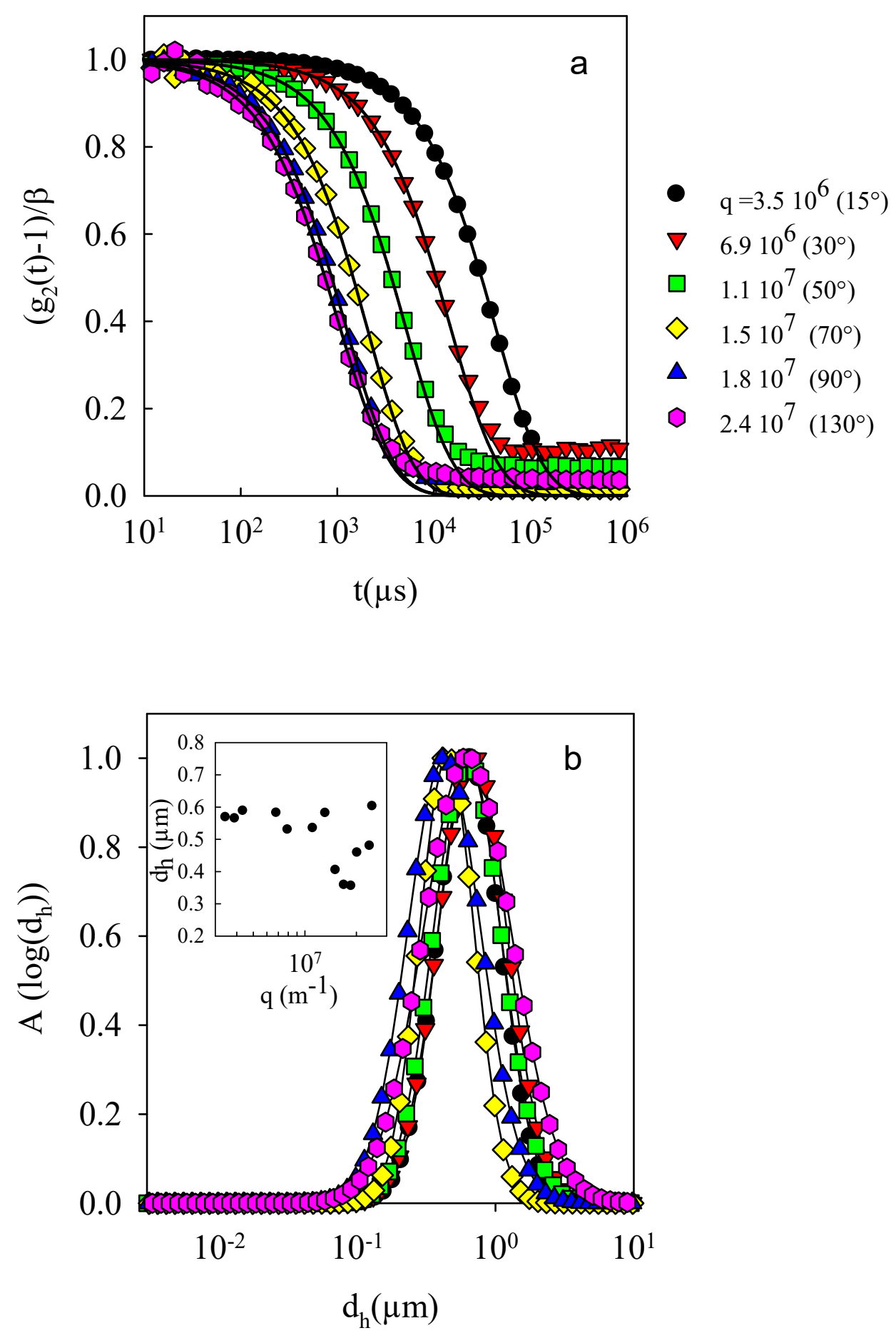

Figure 3. a) Normalized intensity autocorrelation functions at different scattering wave vectors (q) obtained for suspensions of latex particles with $d=0.5 \mu \mathrm{m}$. The corresponding scattering 
angles are indicated in brackets. The solid lines represent fit results to Eq. 14. b) Distributions of the hydrodynamic diameter corresponding to the fit results shown in figure $3 \mathrm{a}$. The inset shows the z-average hydrodynamic diameter as a function of $\mathrm{q}$.

\section{Colloidal particles in seawater}

The capacity to detect and characterize colloidal nanoplastics in seawater was tested by investigating samples of seawater. The seawater was filtered through $0.8 \mu \mathrm{m}$ or $0.45 \mu \mathrm{m}$ pore size filters in order to assess the presence of particles smaller than $0.8 \mu \mathrm{m}$ and smaller than 0.45 $\mu \mathrm{m}$ separately. This is necessary, because the presence of a small amount of large particles can hide the light scattering signal from small particles. Figure 4 shows the q-dependence of $\mathrm{R}_{\theta}$ in comparison with that of Milli-Q water to which sea salt was added at the concentration found in the sea. As expected, adding sea salt caused a small increase of the scattering intensity with respect to pure water shown Figure $1 \mathrm{a}^{19}$.

The amount of light scattered by seawater filtered through $0.45 \mu \mathrm{m}$ pores was within the experimental error the same as for salted milli-Q water over the whole q-range. Considering results obtained on model latex particles discussed in the previous section, such a result would be obtained for suspensions of latex particles with $\mathrm{d}=0.2 \mu \mathrm{m}$ only if $\mathrm{C}<10^{-6} \mathrm{~g} / \mathrm{L}$ and for particles with $\mathrm{d}=0.5 \mu \mathrm{m}$ only if $\mathrm{C}<10^{-7} \mathrm{~g} / \mathrm{L}$. The implication is that the concentration of particles in this sample of seawater with $\mathrm{d}$ between 0.2 and $0.45 \mu \mathrm{m}$ was less than $10^{-6} \mathrm{~g} / \mathrm{L}$, where we assume that the refractive index increment and the density of the particles are close to that of polystyrene, which is the case for most types of nanoplastics. Of course, this does not exclude the possibility that smaller particles are present in higher concentrations. For instance, the excess 
scattering intensity of very dilute suspensions of particles with $d=20 \mathrm{~nm}$ is a thousand times less than for $\mathrm{d}=0.2 \mu \mathrm{m}$ at the same mass concentration.

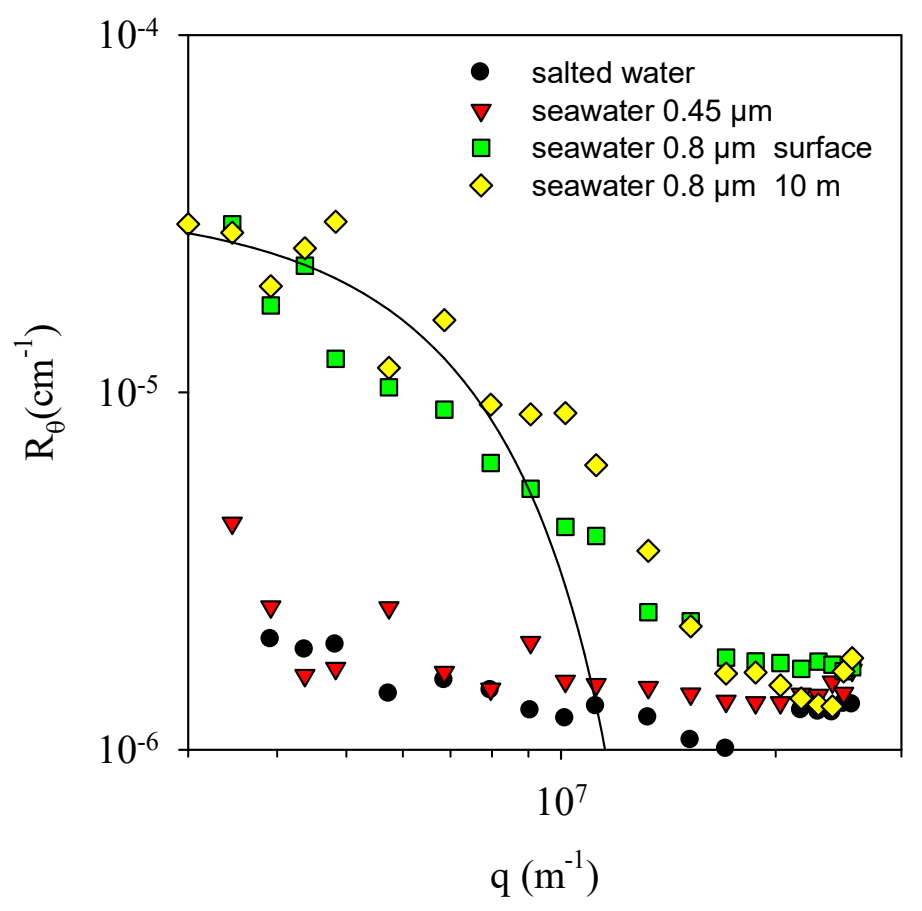

Figure 4. Dependence of the Rayleigh ratio on the scattering wave vector for seawater filtered using different pore sizes. For comparison, the results for Milli-Q water with added sea salt are also shown. The solid lines represent a fit to Eqs 3 and 6 with $d=0.6 \mu \mathrm{m}$.

The time averaged value of $R_{\theta}$ of seawater filtered through $0.8 \mu \mathrm{m}$ pores was much larger and decreased strongly with increasing $\mathrm{q}$, which shows that it was dominated by the scattering from large particles. The solid line through the data represents a fit to monodisperse spherical particles with $\mathrm{d}=0.6 \mu \mathrm{m}$. The deviation at $\mathrm{q}>10^{7} \mathrm{~m}^{-1}$ means that the particles are not monodisperse spheres, as might be expected. Comparison with the results obtained for the latex particles with $d=0.5 \mu \mathrm{m}$ shows that the concentration of particles in the seawater with $d$ 
between 0.45 and $0.8 \mu \mathrm{m}$ not more than $10^{-6} \mathrm{~g} / \mathrm{L}$ assuming that their refractive index and density are close to that of polystyrene. Results obtained with seawater sampled at different locations and different depths were similar.

Figure 5 shows the scattering intensity as a function of time of seawater filtered through $0.8 \mu \mathrm{m}$ pores taken at the surface and a depth of $10 \mathrm{~m} . \mathrm{R}_{\theta}$ fluctuated slowly with time, indicating that the number of particles in the scattering volume was not large, as was discussed above. However, the average value of $\mathrm{R}_{\theta}$ was the same at the two different depths. Results obtained with seawater samples taken at the surface of other locations were similar.
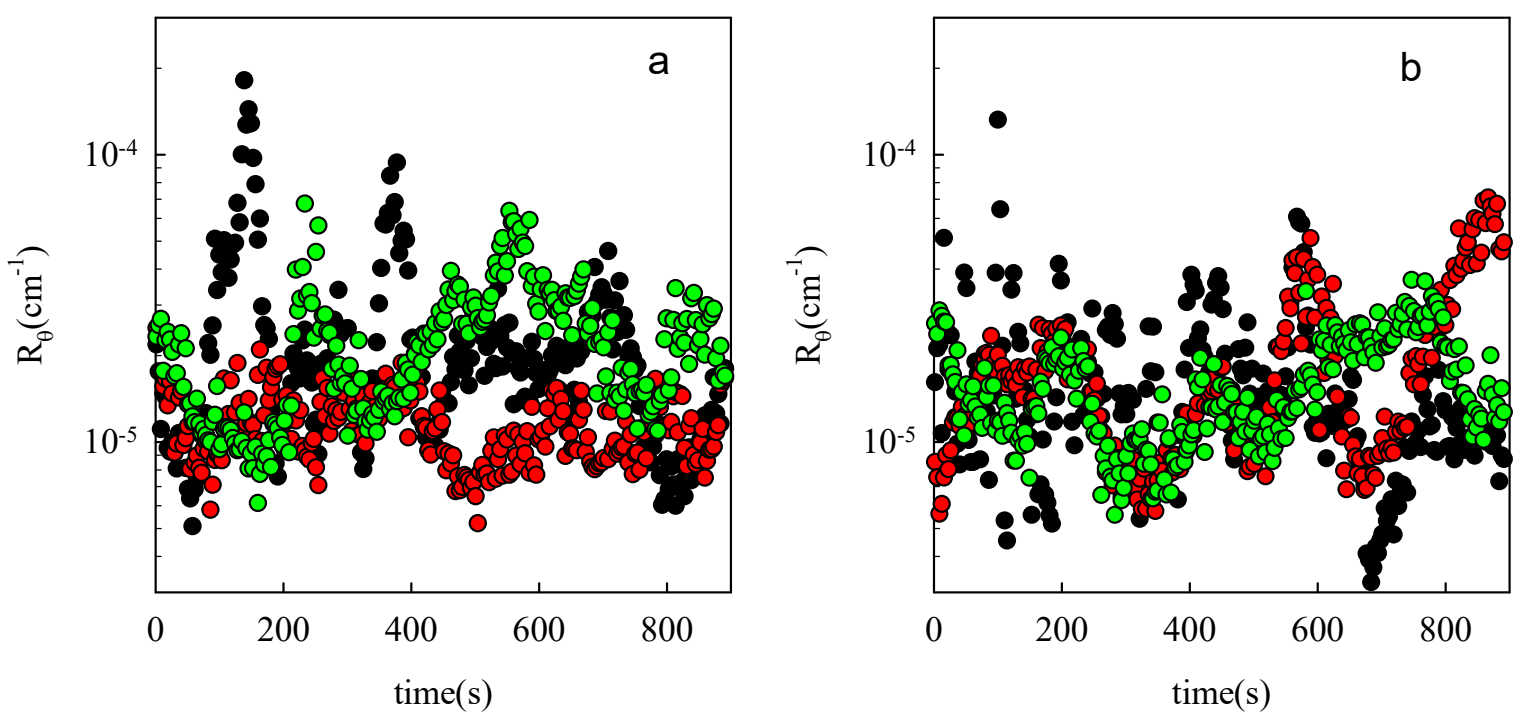

Figure 5. Time dependence of $R_{\theta}$ at $\mathrm{q}=3.9 \times 10^{6} \mathrm{~m}^{-1}\left(\theta=17^{\circ}\right)$ for suspensions of seawater filtered through $0.8 \mu \mathrm{m}$ pore size filters taken at the surface (a) and $10 \mathrm{~m}$ depth (b). Three measurements are shown for each sample. 
Autocorrelation functions of seawater filtered with pore size $0.45 \mu \mathrm{m}$ did not show significant relaxation with $\left(\mathrm{g}_{2}(\mathrm{t})-1\right) \approx 0$ for $\mathrm{t}>1 \mu \mathrm{s}$. This is expected as the scattering by seawater is caused by density fluctuations and diffusion of ions, which relax on timescales shorter than 1 $\mu \mathrm{s}$. Figure 6a shows examples of normalized intensity autocorrelation functions obtained at different scattering angles for seawater filtered with pore size $0.8 \mu \mathrm{m}$. Notice that results obtained at higher scattering angles were not trustworthy, because the scattering intensity was close to that of seawater, see figure 4 . The correlation functions show a well-defined fast decay followed by an ill-defined slow decay. The fast decay is due to diffusion of particles, whereas the slow decay is caused by fluctuations of the number of particles in the scattering volume.
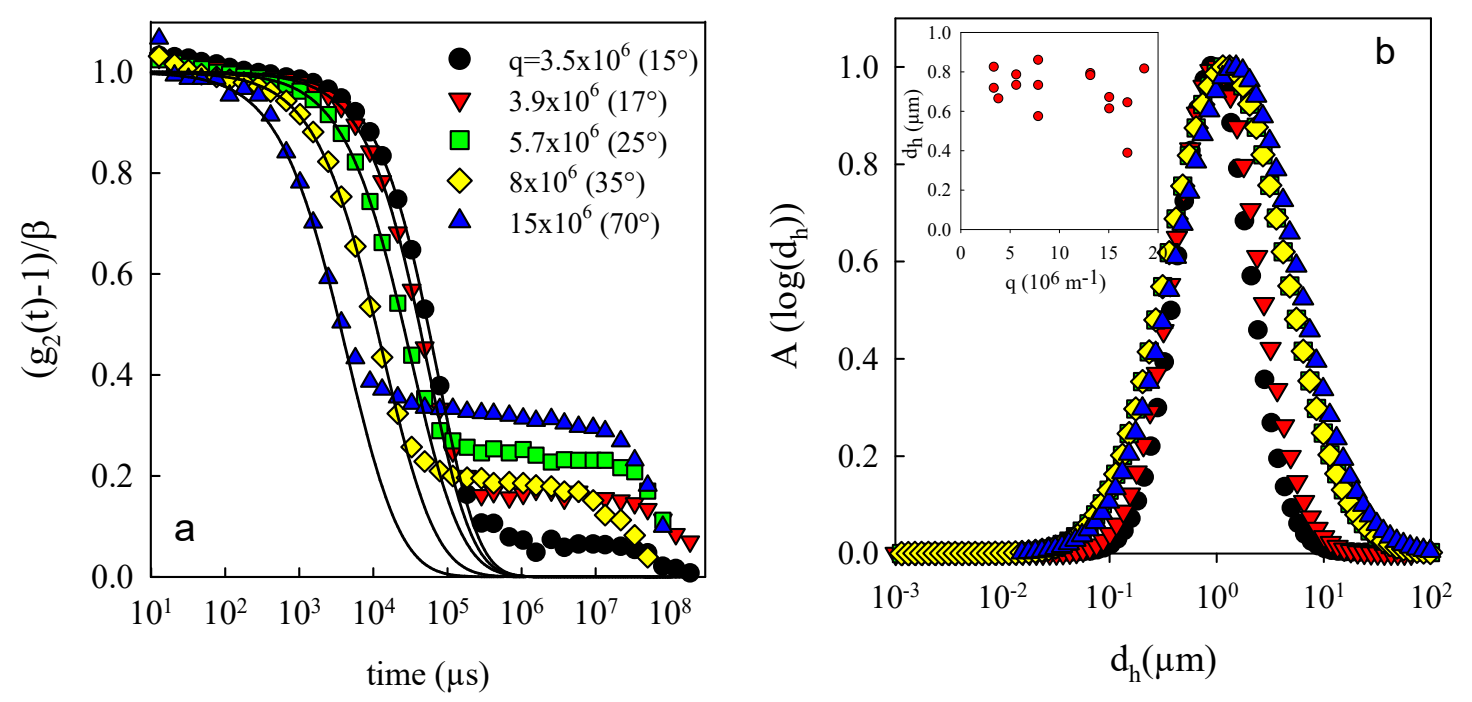

Figure 6. a) Normalized intensity autocorrelation functions at different scattering wave vectors obtained for seawater filtered through $0.8 \mu \mathrm{m}$ pores. The solid lines represent fit results to Eq. 14. b) Distributions of the hydrodynamic diameter corresponding to the fit results shown in Figure 6a. The inset shows the z-average hydrodynamic diameter as a function of $\mathrm{q}$. 
The fast decay was analyzed in terms of a relaxation time distribution that was converted into a distribution of $d_{h}$. The fit results are shown as solid lines in Figure $6 a$, and the corresponding size distributions are shown in Figure 6b. In most cases, z-average hydrodynamic diameters between 0.6 and $0.8 \mu \mathrm{m}$ were obtained consistent with the diameter obtained from fitting the structure factor $(0.6 \mu \mathrm{m})$. The relatively weak dependence of $d_{h}$ on q implies that the particles were roughly spherical and not very polydisperse, but the structure factor shows that they are not perfect monodisperse spheres either. Notice that the size distribution extents to sizes larger than the pore size. The reason is that the analysis method gives a distribution of sizes even if the particles are monodisperse. This can be clearly seen from the results on monodisperse latex particles shown in the previous section. The average diameter does, however, corresponds to the true average diameter. A second reason why the distribution extents to larger values than the nominal pore size is that the $0.8 \mu \mathrm{m}$ filters contain a distribution of pore sizes and may therefore allow some larger particles to pass..

\section{DISCUSSION}

It was demonstrated here that it is possible to quantitatively characterize colloidal particles in aqueous suspension with static and dynamic light scattering as long as they scatter significantly more than water and the scattering volume contains at least a few tens of particles. These limitations depend on the size, shape, polydispersity and refractive index increment of the colloids. Monodisperse spherical latex particles with $d=0.2 \mu \mathrm{m}$ could be reliably characterized by static light down to $\mathrm{C}=10^{-5} \mathrm{~g} / \mathrm{L}$. Latex particles with $\mathrm{d}=0.5 \mu \mathrm{m}$ could be characterized by static light scattering measurements down to $\mathrm{C}=10^{-6} \mathrm{~g} / \mathrm{L}$, but only down to $\mathrm{C}=10^{-5} \mathrm{~g} / \mathrm{L}$ by DLS. Of course, there is not a sharp boundary between concentrations that can and that cannot be 
characterized by light scattering techniques. It is simply the case that the results become progressively less reliable when the concentration decreases.

For samples of seawater, we found that the concentration of colloids with diameters between 0.2 and $0.8 \mu \mathrm{m}$, was not more than $10^{-6} \mathrm{~g} / \mathrm{L}$ assuming that they have the same refractive index increment and density as polystyrene. This concentration was barely sufficient for quantitative characterization by light scattering. The scattering of seawater filtered through 0.45 $\mu \mathrm{m}$ pores was within the experimental error the same as that of salted water. This means that the intensity detected for seawater filtered through $0.8 \mu \mathrm{m}$ pore size filters is due to scattering by colloids with diameters between $0.45 \mu \mathrm{m}$ and approximately $0.8 \mu \mathrm{m}$.

These results confirm and complement results obtained with other samples of seawater by Ter Halle et $\mathrm{al}^{10}$. However, these authors did not perform static light scattering measurements and were therefore not able to quantitatively estimate the concentration of colloidal particles. They used different DLS equipment that allowed measurements only at a single high scattering angle $\left(\theta=170^{\circ}, \mathrm{q}=2.5 \cdot 10^{7} \mathrm{~m}^{-1}\right)$. As we showed above, at this q-value the scattering intensity was very close to that of seawater itself, and it was not possible to characterize the particles by DLS directly in seawater at $\theta=170^{\circ}$. Therefore, Ter Halle et al. concentrated $1 \mathrm{~L}$ of seawater by a factor 200 using ultrafiltration, which allowed them to obtain an autocorrelation function at $\theta=$ $170^{\circ}$ similar to those shown in Figure 3. However, there is a risk that this procedure introduces colloids into the sample.

Unfortunately, DLS cannot inform about the chemical composition of the detected particles. It is therefore not possible to determine whether the detected colloids are actually nanoplastics. In fact, it is likely that mineral particles are present. Therefore, we need to consider 
how light scattering results depend on the type of material. The radius of gyration and the hydrodynamic radius do not depend on the material. However, the light scattering intensity of particles with a given size and at a given weight concentration is proportional to their density and the square of their refractive index increment. Mineral particles are denser and have a larger refractive index increment ${ }^{20}$. Therefore the estimated particle concentration would be even lower if it was assumed that they consisted of minerals instead of plastic.

If we consider that the amount of 'lost plastic', which is estimated at about $10^{14} \mathrm{~g}{ }^{5}$, is distributed equally in the form of colloids in the oceans with a total volume of about $10^{21} \mathrm{~L}$, the expected concentration of nanoplastics is at most $10^{-7} \mathrm{~g} / \mathrm{L}$, which was shown here to be below the limit of detection by light scattering techniques. We did not observe major differences in the amount of larger colloids for the seawater samples taken at different locations. However, these samples were all taken near the coast of Europe and may therefore not be representative of the global average concentration. On the other hand, Erikson et al. ${ }^{5}$ found that the distribution of microplastics (between 0.33 and $1 \mathrm{~mm}$ ) in the North Atlantic was within a factor of 2 the same as in the other oceans. In addition, some of the samples presented here were taken in the Mediterranean sea which is known to be a hotspot of plastic pollution ${ }^{21}$. More measurements of the concentration of colloids at different locations and depths are needed to determine their actual distribution in the oceans.

One also needs to consider that there are many natural sources of colloids in the ocean ${ }^{22-}$ ${ }^{24}$. Interestingly, it has been reported that colloidal particles form spontaneously within hours or days in seawater that was filtered through $0.45 \mu \mathrm{m}$ or $0.22 \mu \mathrm{m}$ pore size filters ${ }^{25,26}$, which was attributed either to association of dissolved organic matter into polymer gel particles ${ }^{25}$ or to spontaneous formation of mineral-organic particles ${ }^{26}$. We have tested whether colloids were 
formed in the filtered seawater samples studied here with time for up to two weeks, but did not observe that the scattering intensity increased in any of the seawater samples that were collected for this study either when filtered through Anatope of MF-Millipore filters. A possible explanation is that the glassware used in the studies reported in the literature slowly released colloidal particles. We have ourselves noted this in the past.

It is likely that the colloids that were detected in the seawater samples studied here were not all nanoplastics and other methodology has to be employed in order to identify the chemical nature of these particles and discriminate plastics from non-anthropogenic particles. The present study confirms that the detection and identification of nanoplastics in the environment is a very challenging research area. It would involve isolating enough colloidal particles from large quantities of seawater to allow for analysis with techniques such as Raman scattering and gas chromatography combined with mass spectroscopy after pyrolysis. The challenge is to remove all non-colloidal material and at the same not to introduce extraneous colloids during the isolation process.

\section{CONCLUSIONS}

The light scattering of seawater samples taken at different spots off the coast of Western Europe and the Mediterranean was within the experimental error the same as for pure water with sea salt added in the same amount as in the seawater after filtration through $0.45 \mu \mathrm{m}$ pore size filters. Comparison with model colloidal particles show that this means that the concentration of colloidal particles with diameters between 0.2 and $0.45 \mu \mathrm{m}$ in the seawater samples was less than $10^{-6} \mathrm{~g} / \mathrm{L}$. Colloidal particles were detected in seawater filtered through $0.8 \mu \mathrm{m}$ pore size filters, but the concentration was at most $10^{-6} \mathrm{~g} / \mathrm{L}$. Dynamic light scattering measured showed that the 
particles had a distribution of sizes with an average hydrodynamic diameter of $0.6 \mu \mathrm{m}$. The concentration of colloidal particles in the seawater samples is too low to be able to characterize their composition. Measurements on model colloidal particles show that characterization of colloidal particles in seawater requires the use of state of the art light scattering equipment that allow for measurements as a function of the scattering wave vector.

\section{AUTHOR CONTRIBUTIONS}

All authors contributed to the conception of the research, interpretation of the results and writing of the article.

\section{FUNDING SOURCES}

This work was funded by Ifremer (convention 17/1212947B, project MERLIN MICROPLASTIQUES) and by the ANR CESA (ANR-15-CE34-0006-02, NANOPLASTICS project).

\section{ACKNOWLEDGEMENTS}

François Galgani is acknowledged for providing the samples at different depths from the Mediterranean Sea. 


\section{REFERENCES}

1. da Costa, J. P.; Santos, P. S. M.; Duarte, A. C.; Rocha-Santos, T., (Nano) plastics in the environmental sources, fates and effects. Science of The Total Environment 2016, 566, 15-26. 2. Andrady, A. L., The plastic in microplastics: a review. Marine pollution bulletin 2017, $119,(1), 12-22$.

3. Barnes, D. K. A.; Galgani, F.; Thompson, R. C.; Barlaz, M., Accumulation and fragmentation of plastic debris in global environments. Philosophical Transactions of the Royal Society B: Biological Sciences 2009, 364, (1526), 1985-1998.

4. Koelmans, A. A.; Besseling, E.; Shim, W. J., Nanoplastics in the aquatic environment. Critical review. In Marine anthropogenic litter, Springer, Cham: 2015; pp 325-340.

5. $\quad$ Eriksen, M.; Lebreton, L. C. M.; Carson, H. S.; Thiel, M.; Moore, C. J.; Borerro, J. C.; Galgani, F.; Ryan, P. G.; Reisser, J., Plastic pollution in the world's oceans: more than 5 trillion plastic pieces weighing over 250,000 tons afloat at sea. PloS one 2014, 9, (12), e111913.

6. Moore, C. J., Synthetic polymers in the marine environment: a rapidly increasing, longterm threat. Environmental research 2008, 108, (2), 131-139.

7. In Proceedings of the International Research Workshop on the Occurrence, Effects, and Fate of Microplastic Marine Debris, University of Washington Tacoma, Tacoma, WA, USA, 2008; Arthur, C.; Baker, J. E.; Bamford, H. A., Eds. University of Washington Tacoma, Tacoma, WA, USA, 2008.

8. Gigault, J.; Pedrono, B.; Maxit, B. t.; Ter Halle, A., Marine plastic litter: the unanalyzed nano-fraction. Environmental Science: Nano 2016, 3, (2), 346-350.

9. Gigault, J.; Ter Halle, A.; Baudrimont, M.; Pascal, P.-Y.; Gauffre, F.; Phi, T.-L.; El Hadri, H.; Grassl, B.; Reynaud, S. p., Current opinion: What is a nanoplastic? Environmental Pollution 2018, 235, 1030-1034.

10. Ter Halle, A.; Jeanneau, L.; Martignac, M.; Jardel̀ E.; Pedrono, B.; Brach, L.; Gigault, J., Nanoplastic in the North Atlantic subtropical gyre. Environmental science \& technology 2017, 51, (23), 13689-13697.

11. Koelmans, A. A.; Kooi, M.; Law, K. L.; van Sebille, E., All is not lost: deriving a topdown mass budget of plastic at sea. Environmental Research Letters 2017, 12, (11), 114028.

12. Shim, W. J.; Hong, S. H.; Eo, S. E., Identification methods in microplastic analysis: a review. Anal Methods In 2017; Vol. 9, pp 1384-1391.

13. Schurtenberger, P.; Newman, M. E., Characterization of biological and environmental particles using static and dynamic light scattering. In IUPAC Series on Analytical and Physical Chemistry of Environmental Systems, Vol. 2., Buffle, J.; van Leeuwen, H. P., Eds. Lewis: Boca Raton, 1993; pp 37-115.

14. Filella, M.; Zhang, J.; Newman, M. E.; Buffle, J., Analytical applications of photon correlation spectroscopy for size distribution measurements of natural colloidal suspensions: capabilities and limitations. Colloids and Surfaces A: Physicochemical and Engineering Aspects 1997, 120, (1-3), 27-46.

15. van de Hulst, H. C., Light scattering by small particles. Academic Press: New York, 1981.

16. Brown, W., Dynamic Light Scattering. The Method and Some Applications. Clarendon Press: Oxford, 1993.

17. Berne, B.; Pecora, R., Dynamic light scattering With Applications to Chemistry, Biology, and physics. Dover Publications: New York, 2000. 
18. Jonasz, M.; Fournier, G., Light scattering by particles in water: theoretical and experimental foundations. Elsevier: London, 2010.

19. Morel, A., Optical properties of pure water and pure sea water. In Optical aspects of oceanography, Jerov, N. E.; Nielson, E. S., Eds. Academic: London, 1974; pp 1-24.

20. Babin, M.; Morel, A.; Fournier-Sicre, V.; Fell, F.; Stramski, D., Light scattering properties of marine particles in coastal and open ocean waters as related to the particle mass concentration. Limnology and Oceanography 2003, 48, (2), 843-859.

21. Cozar, A.; Sanz-Martin, M.; Marti, E.; Gonzalez-Gordillo, J. I.; Ubeda, B.; Galvez, J. A.; Irigoien, X.; Duarte, C. M., Plastic accumulation in the Mediterranean Sea. PloS one 2015, 10, (4), e0121762.

22. Wilkinson, K. J.; Lead, J. R., Environmental colloids and particles: behaviour, separation and characterisation. John Wiley \& Sons: Chichester, UK, , 2007; Vol. 10, p 1-687.

23. Delay, M.; Frimmel, F. H., Nanoparticles in aquatic systems. Analytical and Bioanalytical Chemistry 2012, 402, (2), 583-592.

24. Linders, T.; Infantes, E.; Joyce, A.; Karlsson, T.; Ploug, H.; Hassellov, M.; Skold, M.; Zetsche, E.-M., Particle sources and transport in stratified Nordic coastal seas in the Anthropocene. Elem Sci Anth 2018, 6, (1), art 29.

25. Chin, W.-C.; Orellana, M. V.; Verdugo, P., Spontaneous assembly of marine dissolved organic matter into polymer gels. Nature 1998, 391, (6667), 568.

26. Wu, C.-Y.; Martel, J.; Wong, T.-Y.; Young, D.; Liu, C.-C.; Lin, C.-W.; Young, J. D., Formation and characteristics of biomimetic mineralo-organic particles in natural surface water. Scientific reports 2018, 6, 28817. 